\title{
O NOVO PARADIGMA SISTÊMICO
}

\author{
THE NEW SYSTEMIC PARADIGM
}

Susana Iglesias Webering ${ }^{1}$

\begin{abstract}
Resumo: Nesse trabalho revisaramos algumas teorias para entender as origens e desdobramentos mais recentes do paradigma sistêmico. Bertalanffy introduziu as hipóteses dos sistemas abertos e a teleologia. Le Moigne tratou de desenvolver um modelo para o estudo de um objeto ou fenômeno sistêmico. Maturana e Varela, a teoria da autonomia do ser vivo e a construção do conhecimento. Se o trabalho de Bertalanffy foi recebido com críticas, trabalhos posteriores contemplaram elementos suficientes para o reconhecimento do fenômeno sistêmico, em constante interação com o ambiente, exercendo sua autonomia, construindo e se reconstruindo através de suas interações, o que implicou a (re)introdução da complexidade, a necessidade de ampliar o estudo da organização e, finalmente, a liberdade criadora com os outros, inserida no mundo.
\end{abstract}

Palavras-chave: Paradigma sistêmico; Autonomia; Complexidade; Modelo; Sistemas.

Abstract: In this paper, we review some theories to understand the origins and recent developments of the systemic paradigm. Bertalanffy introduced the hypotheses of open systems and teleology. Le Moigne sought to develop a model for the study of an object or systemic phenomenon. Maturana and Varela, the theory of the autonomy of the living being and the construction of knowledge. If Bertalanffy's work was received with criticism, later work contemplated sufficient elements for the recognition of the systemic phenomenon, in constant interaction with the environment, exercising its autonomy, building and rebuilding through its interactions, implying the (re) introduction Complexity, the need to broaden the study of organization, and finally, creative freedom with others, inserted in the world.

Keywords: Systemic paradigm; Autonomy; Complexity; Model; Systems.

\section{Introdução}

Podemos dizer que o paradigma sistêmico começou a se desenvolver em meados do século XX, quando o Estruturalismo parecia ser ainda um novo e promissor paradigma, com um discurso do método inovador, pois analisava o conjunto dos fenômenos por meio da descrição do objeto na sua totalidade, em funcionamento e evoluindo. No entanto, reconhecer a estrutura formada por elementos que estão subordinados a leis do sistema e dotada de capacidade transformadora trazia contradições importantes em relação ao método reducionista e causal. Esse problema foi, em parte, solucionado com a cibernética que restaurou o conceito de projeto, de finalidade e teleologia (LE MOIGNE, 1996, p.68).

\footnotetext{
${ }^{1}$ Doutora em Engenharia de Produção pela Coordenação dos Programas de Pós-Graduação em Engenharia (COPPE) da Universidade Federal do Rio de Janeiro (UFRJ). Dr. em Economia Social pelo Instituto Universitário de Economia Social e Cooperativa (IUDESCOOP), Universidade de Valência, Espanha. Professora adjunta do Departamento de Administração e Turismo (DAT) do Instituto Multidisciplinar (IM), da Universidade Federal Rural do Rio de Janeiro (UFRRJ), Nova Iguaçu, Rio de Janeiro, Brasil. suiwebering@gmail.com
} 
A cibernética, de alguma maneira, invertia a perspectiva modelizadora: encerrava os mecanismos em uma caixa-preta e privilegiava a interpretação dos comportamentos, tendo como referência permanente o projeto do fenômeno modelizado, descrito em relação ao ambiente em que funciona e se transforma (LE MOIGNE, 1996).

A modelização cibernética encontrou a mesma dualidade que o Estruturalismo ao tentar integrar simultaneamente funcionamento e evolução: era preciso enfrentar o desafio do sistema. A integração desses dois paradigmas, que de alguma maneira se complementavam, aconteceria a partir do final da década de 1960 com os fundamentos dos teóricos da Biologia (LE MOIGNE, 1996).

De alguma forma, essa conjunção já havia sido realizada por Bertalanffy na década de 1930, quando desenvolveu a teoria dos sistemas abertos. A percepção estruturalista de analisar o objeto pelo seu próprio funcionamento era central para este autor, que destacou o caráter organístico de determinados sistemas (LE MOIGNE, 1996).

Sistemas organísticos são diferentes dos sistemas tecnológicos pela sua capacidade de autorrestauração. A concepção mecanicista dos sistemas autômatos fracassa quando esses sistemas não conseguem se autorregular seguidamente a perturbações arbitrárias, mesmo que consigam responder a um ilimitado número de perturbações previstas, não conseguem se autorregular a um número indefinido de situações imprevistas. Problemas como este justificavam outro conceito importante, o de ordem hierárquica entre os diversos sistemas existentes no universo, expressa pelas características próprias das suas estruturas e funções (BERTALANFFY, 1973).

A importância dessa teoria não impediu que, anos mais tarde, a proposta de Bertalanffy de uma Theory of General System fosse criticada por parte da comunidade científica. Não obstante, com o embate a que havia chegado o Estruturalismo e os desdobramentos sistêmicos que já vinham acontecendo simultaneamente, tornou-se possível a consolidação de um novo paradigma sistêmico (LE MOIGNE, 1996).

Por conta do seu caráter transformador no campo científico, bem como as controvérsias que incitou, Le Moigne (1996) reconhece, no conjunto de hipóteses trazidas pelas teorias sistêmicas, a qualidade de paradigma, naquele sentido descrito por Kuhn (2006): revoluções científicas implicam uma mudança na concepção de mundo e, após uma revolução, cientistas mudam sua maneira de trabalhar e agir no mundo. Por isso, optamos por manter a interpretação de um paradigma sistêmico.

Nesse trabalho foram revisadas algumas das origens e desdobramentos mais recentes do paradigma sistêmico (WEBERING, 2016). Primeiramente, a partir da teoria 
dos sistemas abertos do biólogo austríaco Ludwig von Bertalanffy (1901-1972) (BERTALANFFY, 1973). Passamos então, ao trabalho do engenheiro e epistemólogo francês Jean-Louis Le Moigne (1931- ), que se dedicou a desenvolver um modelo e novas perspectivas para o estudo de um objeto ou fenômeno sistêmico (LE MOIGNE, 1994, 1996). E, finalmente, as contribuições dos biólogos chilenos Humberto Maturana (nascido em 14/09/1928) e Francisco Varela (1946-2001), que decifraram com sua teoria da autopoiese, a autonomia do ser vivo (MATURANA; VARELA, 1997), para mais tarde, aprofundarem a questão da construção do conhecimento (MATURANA; VARELA, 2005).

\section{Paradigma Sistêmico}

Bertalanffy teve o mérito de forçar a entrada e o reconhecimento de duas hipóteses complementares, relativas ao organismo vivo e evolutivo, impensáveis no discurso cartesiano (LE MOIGNE, 1996).

\section{Primeira: a hipótese da abertura ao ambiente ou sistema aberto}

Essa hipótese foi verificada ao se reconhecer o organismo vivo como um sistema aberto que mantém um fluxo contínuo de entradas e saídas, conservando-se através da construção e decomposição de componentes, não desenvolvendo um equilíbrio perfeito, mas mantendo-se em um estado estacionário, que é diferente do seu estado anterior; em alguns modelos o estado de equilíbrio, quando existe, chama-se homeostase. Essa ordem é garantida por uma interrelação dinâmica de processos. Em organismos ou sistemas existe um centro que recombina informações recebidas e as transmite para um fazedor da ação, o qual responde à mensagem recebida. Esse sistema autorregulador garante a estabilização ou a direção da ação a ser implementada pelo sistema. Esse processo é uma resposta às desordens do próprio sistema ou do ambiente em que está inserido, tais forças desordenadoras são chamadas entropia (BERTALANFFY, 1973).

O paradigma estruturalista havia reconhecido o caráter global ou de totalidade das estruturas e ao anexar a cibernética se deparou com o problema da modelização do sistema fechado. De acordo com Le Moigne foi "excepcional a intuição de Bertalanffy" quando denominou teoria dos sistemas abertos, a teoria que daria suporte ao paradigma organicista, cuja característica fundamental "representar os objetos no seu substrato", significa "representá-los abertos ao seu ambiente, mesmo que este não possa nunca ser exaustivamente descrito" (LE MOIGNE, 1996, p.72). Mais tarde, ao perceber a 
possibilidade de generalizar a ideia de sistemas abertos, Bertalanffy propôs o conceito de Sistema Geral. Começava a ser reconhecido um outro caminho possível para o fazer científico, em contraste à ideia de sistemas isoláveis e controláveis.

Segunda: a hipótese teleológica

Essa hipótese é verificável na finalidade ou direção do funcionamento sistêmico, o que se denomina teleologia. Três modelos sistêmicos simulam o comportamento teleológico. Primeiro, o de equifinalidade, que é a tendência para um mesmo estado final, partindo de diferentes estados iniciais e percorrendo diferentes caminhos. Segundo, a retroação, que implica uma conservação homeostática ou estacionária, a busca de um objetivo. Terceiro, comportamento adaptativo, em que por funções adaptativas o sistema demonstra um comportamento adaptativo, como ensaios de diferentes modos e meios para atingir sua finalidade (BERTALANFFY, 1973).

Bertalanffy já havia dado destaque ao conceito de organização, que veio a ganhar cada vez mais importância nas teorias sistêmicas (LE MOIGNE, 1996), uma vez que ordem hierárquica, controle, crescimento e diferenciação são características organizativas, quer de um organismo vivo, quer de uma sociedade.

Outro fenômeno considerado, o isomorfismo entre as unidades sistêmicas: são as semelhanças entre leis que explicam o comportamento ou o desenvolvimento de unidades ou populações destas. Isso explica porque modelos, conceitos e leis parecidos apareceram em campos diferentes, ou os mesmos princípios descobertos várias vezes. Os isomorfismos ocorrem também em situações que não podem ser analisadas quantitativamente, mas podem induzir o raciocínio qualitativo (BERTALANFFY, 1973, p.74).

\section{General System Theory}

A ideia de Bertallanfy de uma General System Theory surgiu por um conjunto de fatores, tendo sido exposta publicamente pela primeira vez em 1945 por meio de um artigo. Em 1954 fundou com o matemático Anatol Rapoport a Society for General Systems Theory, que logo em seguida passou a se chamar Society for General System Research, tendo mais recentemente mudado de nome outras duas vezes, International Society for General Systems Research e International Society for the Systems Sciences. O livro General System Theory foi publicado em inglês em 1968 (LUHMANN, 2010). 
Esses esforços se deram, pois o elemento sistêmico vinha sendo reconhecido em diferentes áreas, mas não respondia às condições necessárias para o procedimento analítico que dominava a ciência clássica, cujas condições exigem: primeiro, que as interações entre as partes sejam fracas o suficiente a ponto de ser desprezadas para as finalidades de determinados tipos de pesquisa, nessas condições, a análise das partes pode ser esgotada nela mesma; segundo, que as relações entre as partes sejam lineares, permitindo a condição de aditividade, ou seja, tanto o todo quanto as partes podem ser tratados da mesma forma, os processos parciais podem ser sobrepostos ou somados para que se obtenha o processo total. Ao contrário disso, os sistemas são complexidades organizadas, possuem fortes interações e/ou interações não triviais (BERTALANFFY, 1973, p.38).

Portanto, enfoques sistêmicos surgiram com o intuito de solucionar esses problemas, obviamente não de maneira homogênea, inclusive apresentando em alguns casos modelos que se confundiam, como mencionado na explicação das duas hipóteses anteriormente, em comum: a qualidade de sistêmicos. Bertalanffy sintetizou então, algumas características gerais dos diferentes enfoques sistêmicos, dando origem ao que denominou General System Theory, cujo objeto seria a “formulação de princípios válidos para 'sistemas' em geral", chegando a prever que seu trabalho sofreria resistência (BERTALANFFY, 1973, p.60).

Os isomorfismos eram encontrados em diferentes áreas devido a comportamentos semelhantes mesmo entre entidades intrinsecamente diferentes, possibilitando que concepções sistêmicas fossem apropriadas pelas ciências do homem, como a Psicologia, Economia, Sociologia, Ciências Sociais e História ou mesmo reconhecida em teorias já existentes nessas áreas (BERTALANFFY, 1973). Por exemplo, nos modelos de equilíbrio e desequilíbrio existentes em teorias econômicas, com registro já no século XVII. Portanto, "na tentativa da Society for General Systems Theory, não se pode falar em um descobrimento específico no campo do sistêmico, mas sim em uma variante daquele pensamento já antigo sobre a estabilidade" (LUHMANN, 2010, p.61).

A partir da concepção de que a ciência empreende um "esforço nomotético", ou seja, não sendo a descrição de singularidades, "mas a ordenação dos fatos e a elaboração de generalidades", a ciência social poderia ser a ciência dos sistemas sociais (BERTALANFFY, 1973, p.259). Os primeiros esforços foram reconhecidos nos estudos sobre os sistemas socioculturais e no funcionalismo, que implicavam o exame dos fenômenos em relação ao todo. Este último encontrou sua principal crítica no fato de ter 
as consequências históricas, os processos interiormente dirigidos, transformações socioculturais, entre outros fenômenos subestimados. A teoria geral dos sistemas procurava reconhecer a manutenção e a mudança, a preservação do sistema e o conflito, o universo humano simbólico e suas transformações, servindo apenas "de esqueleto lógico" para o desenvolvimento teórico posterior, sendo de utilidade para entidades amplamente heterogêneas. Sua dificuldade manifesta-se não somente em função da complexidade dos fenômenos, mas também pela dificuldade na definição das entidades que devem ser consideradas (BERTALANFFY, 1973, p.261).

Em meados do século XX, as leis aplicadas aos fenômenos sociais já eram bastante conhecidas no âmbito da estatística pelas regularidades de entidades sociais e na economia matemática pelo método hipotético-dedutivo. Para o desenvolvimento dos valores humanos, também começavam a aparecer enfoques para tratar questões comportamentais fornecidos, por exemplo, pela teoria dos jogos, do processo decisório, teoria da informação; elementos até então considerados fora da ciência (BERTALANFFY, 1973).

Assim, tornou-se possível e aceitável a regularidade de leis em fenômenos sociais. Têm mérito análises relativas à organização e dinâmica de determinados sistemas sociais, quando restritas a pequenos campos de atividade humana. A complexidade reside nas discussões relativas às tentativas de lidar com regularidades na macro-história (BERTALANFFY, 1973).

Tem-se consciência das vantagens e desvantagens da adoção de modelos. A vantagem é a possibilidade de desenvolvimentos teóricos que permitam explicações e premissas. O perigo é a excessiva simplificação (BERTALANFFY, 1973, p. 266). Independentemente das divergências, o caráter organísmico dos sistemas sociais permitiu uma análise cíclica de fenômenos históricos e sociológicos, às vezes não necessariamente em termos de ciclo vital, mas em termos de flutuações. Isso foi possível devido ao isomorfismo de leis ou de ordens em diferentes campos, em oposição ao reducionismo, uma espécie de perspectivismo sistêmico (BERTALANFFY, 1973).

De fato, o projeto de Bertalanffy foi considerado ambicioso por parte da comunidade científica (LE MOIGNE, 1996, p.74). Contudo, isso não foi consenso, pois eram críticas basicamente ideológicas que visavam a estabilidade ou o status quo dominante. De acordo com Luhmann, "a crítica nunca foi apropriada" e, "como se diz hoje, ela é compreensível, mas não justificável, no sentido de não ter sido uma crítica com fundamento teórico suficiente" (LUHMANN, 2010, p. 72). 


\section{Uma Teoria de Modelização}

Apesar das polêmicas, estavam lançados os desafios no sentido do desenvolvimento de um paradigma que contemplasse os objetos ou fenômenos complexos, compreendidos como sistemas abertos e com finalidades. O Estruturalismo e a caixa-preta da cibernética não haviam dado conta e a integração destes paradigmas iria ocorrer no final da década de 1960, tendo como base experiências procedentes da Biologia (LE MOIGNE, 1996, p.69). Como exemplo, quase simultaneamente Le Moigne lançava “A Teoria do Sistema Geral”, Morin “O Método”, Maturana e Varela começavam a decifrar o organismo vivo de identidade própria e autorreferenciado, a autopoiese.

A partir de então, começou a haver um esforço científico, contribuindo com o desenvolvimento de uma teoria do sistema geral, como metodologia própria de investigação, servindo tanto para a exposição das propriedades de determinado objeto (sempre objeto ou fenômeno), quanto para a modelização ou desenvolvimento de um projeto. Essa metodologia permite representar objetos de qualquer natureza, desde que sistêmica. Seguindo a lógica organísmica, quem modeliza um objeto é dotado de um projeto, identificável através da interpretação dos comportamentos. As leis causais são utilizadas para a realização do projeto, que existiu primeiramente na mente do modelizador. A estrutura não explica necessariamente a função ou evolução, estas serão pertinentes aos projetos considerados (LE MOIGNE, 1996).

Le Moigne (1996) explica a utilização da terminologia Teoria do Sistema Geral e não Teoria Geral dos Sistemas, como é de costume, tendo como base a General System Theory de Bertallanfy. O termo em inglês gerou ambiguidades ao ser traduzido para diversos idiomas, interpretado por vezes como uma Teoria Geral, outras como Sistema Geral. Em sua obra, a qualidade geral aparece atribuída a sistema, não a teoria; confirmaria o fato de ter fundado na década de 1950 a Society for General Systems Research, que publicava a General System Yearbook.

Uma linha de pesquisadores se preocupou mais por definir as propriedades do Sistema Geral, como referência para a modelização de sistemas e teorias. Para Le Moigne (1996, 1994), o uso expandido dos termos "análise de sistemas" ou "abordagem sistêmica" está impregnado de referência ao modelo de análise cartesiano. Não se trata de analisar, mas conceber um modelo, de pensamento, de projeto, de um objeto. Para minimizar a ambiguidade, é importante inseri-lo no contexto de um paradigma sistêmico, de um novo discurso do método, que utiliza um objeto artificial como referência, o 
sistema geral, que tem propriedades articuladas a uma teoria. Portanto, uma concepção sistêmica.

E o que é um sistema?

Bertalanffy trabalhou a ideia de sistema como um conjunto de elementos em interação, teria sido mais fácil e aceito se realmente fosse só isso, pois logo se conclui que esta concepção, ainda muito analítica e conjuntista, não era suficiente para o complexo de um sistema (LE MOIGNE, 1996, p. 76).

Buscou-se então outro caminho, partindo de uma intenção: a investigação dos métodos para bem conduzir a razão e representar o mundo cognoscível, emergindo progressivamente um paradigma expresso pelo sistema geral, que existe em determinado ambiente, com finalidades, em atividades de interação constante, cujos resultados contribuem com sua evolução ou extinção. Esse esquema representa muito mais uma descrição do que uma definição, intencionalmente generalizante, mas suficiente para reconhecer um objeto ou fenômeno sistêmico (LE MOIGNE, 1996).

O Sistema Geral permite a passagem da análise à concepção, o que exige conhecimento suficiente para interpretá-lo e antecipar o seu comportamento, um construto humano para representar objetos que o homem quer conhecer. É a consciência de uma ordem, um desenho, resultado de uma longa experiência que responde a um incontável conjunto de objetos diferentes. Essa representação pode variar do intento mais formal e explícito a uma representação mental implícita.

Le Moigne (1994) chama de "projectivismo" essa alternativa ao determinismo. Enquanto deterministas se dividem entre positivistas, einsteinianos, lapacianos, realistas, entre outros; projectivistas se dividem entre epistemologias como a construtivista genética de Piaget, a complexidade de Morin, engenharias com as contribuições de $\mathrm{H}$. Simon.... Essas epistemologias se caracterizam também pela (re)aproximação entre ciência e filosofia, entre natureza e cultura, entre objeto e sujeito (LE MOIGNE, 1994).

Essa disputa suscita o debate que fora silenciado, o debate da complexidade. Porém, nossa capacidade de representar de modo inteligível nossa ação no mundo não deve ser reduzida ao projectivismo ou ao determinismo, mas deve saber tirar o devido proveito de um e de outro. Se o determinismo possibilitou o progresso da ciência, ele vem sendo questionado porque pode ser um caminho adequado a determinados temas e objetos, mas paralisante em outros.

Inspirado pelas rupturas que ocorreram nas ciências e pelas mudanças que engendravam na maneira de pensar a própria ciência, Le Moigne (1994) desenvolveu uma 
proposta para enobrecer as novas ciências - ciências de gestão, da informação, da computação, de decisão - como ciências da autonomia, que naqueles moldes não são reconhecidas como ciências. Para isto, recuperou a obra de Da Vinci (anterior um século a Descartes), que desenvolveu "um método de concepção, não de análise, um método de visualização, não de redução" (LE MOIGNE, 1994, p.41). Para Da Vinci existiam lógicas, não uma única lógica. E Vico com sua Scienza Nuova, publicada em Nápoles entre 1725 e 1744, em que criticou a análise reducionista cartesiana e fundou a construção do conhecimento científico sobre as ciências do gênio (l'Ingenium), não na análise; já que inventar qualquer coisa com base apenas na análise era inviável.

De acordo com Le Moigne (1996, p. 41), “o homem de ciência deve dar a ver (desenhar) o que ainda não foi visto: é um conceptualizador de modelos, de desenhos, de teorias". O homem é criador e sujeito, e "a ciência entendida deste modo não tem como ideal a abordagem assíntota de algumas verdades imanentes: ela quer se edificar (concepção-construção)" (LE MOIGNE, 1994, p.42).

Essa interpretação dá novos rumos à ciência: no sentido de organizar aparências de acordo com um sistema de leis, não em revelar leis universais; no sentido de privilegiar a legitimidade epistemológica das ciências do artificial em relação às ciências naturais ou as ciências de concepção em relação às ciências de análise, restaurando as ciências do gênio. É necessário que se reconheça a cientificidade das ciências do gênio e as epistemologias que lhes dão suporte (LE MOIGNE, 1994).

De acordo com Le Moigne (1996) um projeto sistêmico exige novas perspectivas.

A primeira delas implica o reconhecimento de uma teoria de modelização. Pressupõe a pluralidade dos modelos concebíveis de um mesmo fenômeno, mas sobretudo, a pluralidade dos métodos de modelização. Porque concorda com a impossibilidade de validação universal, a liberdade está no cerne da cognição. "Para arquitetar o conhecimento, já não estaremos exclusivamente reduzidos às receitas dos métodos hipotético-dedutivos: disporemos do campo aberto dos métodos axiomáticoindutivos" (LE MOIGNE, 1996, p.24).

A segunda perspectiva está relacionada ao paradigma da complexidade, que reconhece e aceita a complexidade do fenômeno observado. A delimitação do conhecimento por áreas não dá conta da complexidade dos fenômenos, sim mutila-os, considerando complexo "o que não pode ser resumido a uma palavra chave, o que não pode ser reduzido a uma lei nem a uma ideia simples" (MORIN, 2007, p.5). A inteligibilidade do conhecimento não permite a sua redução: reconhecer a complexidade 
do real gera resistência às nossas racionalizações; a complexidade do real estimula o pensamento complexo. Assim, a experiência humana vem construindo o conhecimento através da sua atitude de espírito científico, de curiosidade, de vontade de conhecer e aprender (LE MOIGNE, 1996).

De acordo com Maturana e Varela (2005), conhecer como conhecemos implica nos reconhecer como seres vivos, autônomos, (auto)-criadores, mas construídos e reconstruídos com os outros, inseridos no mundo, assumindo as responsabilidades de nossas ações. Isto implica um ideal de liberdade diferenciado, não a liberdade individualizada, que prescinde dos outros, mas uma liberdade com os outros, através deles e da natureza e que, por isto mesmo, não pode ocorrer de outra maneira, senão numa base ética e cooperativa.

Terceira perspectiva: tudo é organização. Tem força o conceito de organização pensado enquanto "capacidade de um sistema para, ao mesmo tempo, produzir e produzirse, ligar e ligar-se, manter e manter-se, transformar e transformar-se". Tanto que Morin (2007) considera a teoria da organização a face interna da teoria sistêmica. Essa concepção permite auto-organizar a complexidade da ação, do equilíbrio e da transformação de um sistema. Esse conceito tem poder (ainda não adequadamente explorado), pois a partir dele se compreende o funcionamento do modelo "organizado por construção", "organizante por vocação" e ele próprio "necessariamente organização". A modelização sistêmica tem a capacidade de respeitar a "dialética constitutiva de toda a complexidade: transformar-se funcionando e funcionar transformando-se, mantendo a sua identidade" (LE MOIGNE, 1996, p.28).

Quarta perspectiva: sistema é sistema, não é conjunto. A princípio a análise de sistema implicava que um sistema podia ser analisado por meio do encadeamento e descrição dos seus elementos e suas relações. Desta maneira perde-se a riqueza do conceito de sistema fundado na dialética do organizado e organizante. Sistema não se trata apenas de um conjunto, mas um conjunto complexo. Depois de Bertalanffy (1973), houve um esforço em se desenvolver a capacidade propriamente sistêmica e não conjuntista do conceito de sistema geral. Daí a crítica sobre a prolixa literatura norteamericana sobre a análise de sistemas, que na verdade se revelava analítica. Para superar a análise conjuntista é preciso passar da pergunta “do que é feito?" à pergunta "o que é que faz?". Isto permite que se supere a modelização analítico-orgânica e que passemos a uma modelização sistemo-funcional (LE MOIGNE, 1996, p.31). 
Quinta perspectiva: modelizar é decidir. Como proposta de teorização essa perspectiva pode parecer contraditória: o reconhecimento da liberdade criadora do modelizador. Não deve haver repreensão moral ao modelizador que explicita ou verifica a priori os axiomas sobre os quais vai apoiar progressivamente suas inferências e projeto. A decisão por um ou outro axioma é consequência da livre escolha do modelador.

Um projeto sistêmico exige uma agregação conscienciosa para a sua realização. Reconhecer o mundo em transformação, como a ciência e a construção do conhecimento também transformam se transformando, tal empreendimento de modelização exige novos preceitos, o que Le Moigne (1996) denominou um novo discurso do método, em oposição aos preceitos que dominaram por três séculos as ciências (evidência, reducionismo analítico, causalidades, exaustividade). Também são quatro os novos preceitos.

Preceito de pertinência: o objeto será definido pelas intenções (declaradas ou não) do modelizador, por sua capacidade de desenvolver relações associadas a algumas finalidades perceptíveis e explicáveis. Isto envolve aceitar que a percepção do modelizador e o próprio objeto podem mudar.

Preceito do globalismo: considera que o objeto a ser descoberto está inserido e ativo em um todo maior, compreender este ambiente é condição para o conhecimento do objeto. Não existe a necessidade de preocupação excessiva em captar a sua estrutura interna, uma vez que já se reconhece que a reprodução mais próxima só seria possível ao assumir tal forma.

Preceito teleológico: interpretar o objeto pelo seu comportamento, sem procurar explicar o comportamento com base em alguma lei de eventual estrutura ou causalidade. A racionalidade aqui tende a ser totalizante, procurando considerar fins, meios e suas relações. Ainda que não conheça realmente quais são os fins ou mesmo seja incapaz de dizê-los, mas pode desenvolver algumas hipóteses sobre o que poderiam ser ou tornar-se. A hipótese com base em uma relação causa-efeito não é indispensável, pois a inteligência cognitiva é capaz de substituir esta explicação por outra com base no comportamentofinalidade. Lembrando que o reconhecimento dos comportamentos se dá em relação ao projeto ou modelo como foi atribuído livremente pelo modelizador. Portanto, considerase esse projeto hipotético (LE MOIGNE, 1996, p.56).

Preceito de agregatividade: toda representação é deliberadamente partidária. Busca-se por meio de alguma orientação selecionar os agregados pertinentes, reconhecendo que a objetividade do recenseamento exaustivo é irreal. Aceita-se a interpretação em termos relativos e contingentes. Os objetos que precisam ser 
representados hoje não estão inseridos em uma teia identificável, com comportamentos numeráveis (LE MOIGNE, 1996).

Para realizar esses preceitos, além da descrição formal do que é o fenômeno ou um objeto (ao que se restringiu por muito tempo a ciência), é preciso acrescentar o que acontece quando em contato com o seu ambiente. Isto se chama a definição funcional, experimental ou praxiológica do objeto. A ênfase não está na composição, mas no comportamento. Além da essência e da experiência é preciso conhecer o objeto na sua história (hereditariedade) e no seu devir. Portanto, a explicação precisa ir além e ser também genealógica e genética.

Assim, o "Ser", o "Fazer" e o "Devir" representam a abertura para a representação e o conhecimento do objeto, sua definição ontológica (o que o objeto é), funcional (o que o objeto faz) e genética (o que o objeto devém). Isso implica reconhecer ainda que cada modelagem ou concepção é única (LE MOIGNE, 1996, p.79).

\section{Autopoiese: a autonomia do ser vivo}

Dando continuidade à revisão de teorias que contribuíram para o constructo que se convencionou chamar paradigma sistêmico, a teoria da autopoiese decifrou a autonomia do sistema organísmico: o ser vivo. Do grego poien significa fazer, gerar; pelo termo, Maturana e Varela (1997) procuraram caracterizar os seres vivos em relação aos não vivos, demonstrando se caracterizarem como sistemas auto-organizados que contêm os seguintes aspectos: autonomia, circularidade e autorreferência (BAUER, 1999).

Para Maturana e Varela (1997), a autopoiese é fator que define sistemas vivos em qualquer parte do universo físico, independentemente de existirem sistemas mais ou menos complexos. Essa afirmação diz respeito ao fenômeno biológico de sistemas autohomeostáticos, que possuem organização própria como variável que os mantém constantes. Ao contrário das máquinas que produzem algo diferente delas mesmas (por isso, alopoiéticas), sistemas autopoiéticos reproduzem a si mesmos.

Uma unidade autopoiética pode sofrer deformações para manter sua autopoiese em consequência das condutas autopoiéticas de outros organismos. É considerado o domínio de interações de uma unidade autopoiética todas as deformações que ela pode experimentar para não perder sua autopoiese. Esse domínio é determinado pela maneira como cada unidade realiza esse processo e pela sua estrutura naquele dado momento, o que implica limites: a possibilidade de desorganização e morte. No entanto, 
um sistema pode sofrer interações que afetam sua identidade. Como o domínio de interações de um sistema é autopoiético, há agentes deformantes que um observador pode perceber, mas o sistema autopoiético não, em função de não ter outras maneiras de compensá-lo. O domínio das interações que participa sem perder sua identidade é considerado seu domínio cognoscitivo e equivale ao seu domínio condutual, ou seja, toda conduta é expressão do conhecimento. Porém, o domínio cognoscitivo está subordinado à autopoiese; significa que para mantê-la pode haver transformação, o conhecimento não é absoluto. Sendo assim, a maneira como é realizada a autopoiese se transforma, o domínio cognoscitivo e condutual também. Sistemas autopoiéticos são auto-conscientes, com capacidade de auto-observação (MATURANA; VARELA, 1997).

A lógica universal para os domínios fenomenológicos de sistemas autopoiéticos se refere "às relações possíveis entre as unidades que os originam, e não às propriedades das unidades geradoras que determinam a maneira como são realizadas tais relações em cada caso" (MATURANA; VARELA, 1997 p.120).

Nos organismos vivos, a auto-organização define e configura o sistema, por sua vez, operacionalizado através da estrutura. Isto é paradoxal, pois ao mesmo tempo em que são autônomos estão submetidos a um determinismo estrutural, não significando que sejam pré-determinados, uma vez dotados de capacidade própria de mudança autorreferenciada, ou seja, determinam seu comportamento a partir da interpretação própria das influências sofridas. Seres vivos vivem no conhecimento e conhecem no viver. Este fenômeno os transforma ao mesmo tempo em que transformam o seu meio, ou seja, ambos se modificam (MARIOTTI, 1999).

Por isso, Maturana e Varela (1997) falam de circularidade, autonomia e autorreferência, ao mesmo tempo associadas ao meio, dependente e em interação com ele, gerando o acoplamento estrutural, outro elemento importante nessa teoria e que exige um enfoque novo, pois um sistema autopoiético só existe como tal no espaço onde se desenvolve, o observador, por sua vez, através da sua própria autopoiese gera um fenômeno descritivo. Porque cada sistema em si é uma unidade em sua totalidade a cada instante. Sistemas autopoiéticos têm um contexto de funcionamento próprio, independente das correlações que um observador possa desenvolver em relação a ele, este tem sempre um domínio cognoscitivo relativo do fenômeno.

O desenvolvimento dessa teoria inaugurou o fenômeno interpretativo da unidade viva e o que ela faz de si mesma. As funções da reprodução e da evolução em Maturana e Varela (1997) aparecem de forma secundária. O cerne de seus estudos é o sistema vivo 
autônomo, auto-organizado. Para esses autores, os impactos da ideia darwiniana de evolução - com ênfase na seleção natural e na aptidão - foram muito além de uma explicação da diversidade dos sistemas vivos e sua origem. A forma como foi usada além da Biologia para justificar a sociedade competitiva, a subordinação econômica, política e social "não é válida". Nesses termos, a espécie humana é tratada como entidade histórica permanente, apenas mantida por indivíduos "transitórios e dispensáveis" (MATURANA; VARELA, 1997, p.114). Logicamente a humanidade evolui enquanto espécie, pois a competência do organismo vivo conduz a um caminho evolutivo. Contudo, o uso dessa ideia por meio da Biologia ou em outras áreas científicas não justifica o argumento de que cabe ao indivíduo deixar que os fenômenos naturais sigam seu rumo. Maturana e Varela (1997) demonstraram que não é válido interpretar o indivíduo como subordinado à espécie "porque a fenomenologia biológica é fundamentada pela fenomenologia individual, e sem indivíduo não há fenomenologia biológica alguma" (MATURANA; VARELA, 1997, p.114). Nesse sentido, a biologia não pode ser empregada para “justificar a qualidade de prescindíveis dos indivíduos em benefício da espécie, da sociedade ou da humanidade sob pretexto de que seu papel é perpetuá-las, biologicamente, os indivíduos não são prescindíveis" (MATURANA; VARELA, 1997, p.114).

\section{Para a construção do conhecimento}

Com base nas pesquisas sobre a autonomia do ser vivo, anos mais tarde os autores aprofundaram a questão da construção do conhecimento em seu livro A árvore do conhecimento, partindo do simples pressuposto que a vida é um processo de conhecimento e constitui um objetivo compreendê-la. Sendo assim, é preciso entender como os seres vivos conhecem o mundo, fundando o que se considera uma biologia da cognição. Reconhecer que o mundo não é pré-construído, mas construído por nós e nós por ele em uma interação constante, transforma a visão dominante, objetiva e representacionista. Por conseguinte, transforma também o papel do homem no mundo, somos convidados a assumir nossas responsabilidades sobre como empreendemos nossas ações: autonomia e dependência complementam uma à outra; os seres vivos e o mundo estão interligados e não podem ser compreendidos em separado (MARIOTTI, 2005).

Isto não significa que se deve negar toda e qualquer legalidade, ou assumir que tudo é relativo, mas deve-se buscar um equilíbrio entre os extremos representados pelo 
objetivismo e o idealismo, para encontrar as regularidades percebidas no mundo, como são experimentadas a cada momento e, portanto, não são independentes de nós a ponto de garantir a estabilidade e objetividade. As regularidades estão relacionadas à nossa história biológica e social, não havendo razão absoluta nas descrições. Sob essa concepção, se reconhece que o observado se caracteriza por regularidades e mutabilidades, assim como nossa própria experiência. Deste modo, nosso domínio cognitivo está imerso em um círculo de interações cujos resultados dependem do modo como se desenvolve este círculo, ou seja, a própria história. Pensar na possibilidade de estar fora deste círculo é acreditar que se pode mudar a natureza da natureza (MATURANA; VARELA, 2005, p. 264).

Maturana e Varela (2005) enfatizam que além de procurar apenas adquirir conhecimento, o homem deve se preocupar com o conhecimento do conhecimento. Este é o grande desafio do homem atual, pois se soubesse que o conhecimento se constrói com os outros seria mais fácil aceitar os outros. Este constitui o fundamento biológico do fenômeno social, que se dá muito mais com base na cooperatividade do que na competitividade. Sem isto, a sociabilização e, consequentemente, a própria humanidade estão comprometidas. Qualquer coisa que destrói ou limita o outro compromete o fenômeno social. Nessas circunstâncias, quando ainda existe convivência, ela se dá de forma indiferente. Somente a instituição de um ideal de transcendência individualista permite pensar que o devir do mundo independe de nós.

Reconhecer a circularidade cognitiva não deve constituir um problema na compreensão do fenômeno do conhecimento, mas contribuir no sentido de reconhecer que "o conhecimento do conhecimento obriga" vigilância constante (MATURANA; VARELA, 2005, p.267). Porque se sabemos que o mundo que vemos é um mundo construído com os outros somos capazes de desenvolver ações comprometidas e éticas, respeitando o fundamento biológico e social do ser humano, a reflexão sobre o que "ele é capaz e que o distingue" torna-se central. Assim, desenvolver qualquer concepção exige consciência da "situação em que se está", olhando-a desde uma perspectiva mais abrangente para que o outro também tenha o seu lugar (MATURANA; VARELA, 2005, p.267).

No caso de analisar a sociedade como um sistema autopoiético, pois segundo os autores estaria em conformidade com os termos propostos, teríamos duas hipóteses. $\mathrm{Na}$ primeira, a fenomenologia individual dos homens estaria subordinada à autopoiese da sociedade (vista como um sistema de primeira ordem), havendo o risco da função 
autopoiética dos indivíduos restringir-se a um papel alopoiético dentro dela, o que daria sentido à ideia de "qualquer coisa pelo bem da humanidade", sendo muito difícil os homens interferirem na dinâmica dessa sociedade. Na segunda, como uma sociedade só permanece em equilíbrio enquanto satisfaça a autopoiese de seus indivíduos, os seres humanos podem procurar concatenar-se de outras maneiras para desenvolvê-la. Caso contrário, a sociedade em si passa a ser um sistema alopoiético, deixando de haver a organização sistemática entre seus componentes, sua função seria apenas satisfazer as necessidades materiais, intelectuais e estéticas de seus indivíduos, fornecendo-lhes um meio interessante "para sua existência como sistemas dinâmicos e mutáveis". Portanto, há um estado de tensão. Os próprios autores sinalizaram que o problema entre fenomenologia biológica e social era difícil de ser respondido (MATURANA; VARELA, 1997, p.115).

Como o homem não é apenas um ser natural, mas também cultural, desenvolve o condicionamento e realimentação do seu ciclo. A maneira como o homem vive a sua autopoiese o diferencia dos demais seres vivos, o que também lhe confere, por vezes, um caráter autoagressor (MARIOTTI, 1999) ou patológico (FROMM, 1983). De acordo com Fromm (1983), para desenvolver qualquer análise referente a essa problemática é preciso enfrentar o desafio de deduzir elementos comuns da "existência total" humana, em diversos tempos e culturas, "assim como o homem transforma o mundo ao seu redor, ele também se autotransforma no processo da História. Ele é, por assim dizer, a sua própria criação". Porém, assim como o homem só pode modificar os materiais naturais segundo a natureza destes, ele só pode se autotransformar segundo a sua própria natureza. No processo da História o homem desenvolve seu potencial, de acordo com suas possibilidades. De acordo com Fromm, as principais tendências do homem resultam de sua existência total, algumas delas conduzem à saúde e felicidade, outras à doença e infelicidade. Uma determinada ordem social não cria essas tendências fundamentais, mas estabelece quais, que existem em número limitado, deverão tornar-se manifestas ou dominantes. O homem é sempre, em qualquer cultura, manifestação da natureza humana, manifestação essa que é, em sua expressão específica, determinada pelos arranjos sociais sob os quais ele vive (FROMM, 1983, p.28).

$\mathrm{Na}$ modernidade se disseminou um ideal de racionalidade que, por meio de diversos fatores e acontecimentos, contribuiu com o desenvolvimento de uma sociedade de mercado. A organização do trabalho capitalista, da economia e organizações transformaram as relações sociais, exacerbando a competitividade, o individualismo e 
utilitarismo. Essa configuração simplifica a condição humana, contradiz o humano, suas potencialidades e a vida em sociedade, o que levou Fromm (1983) a concluir que se trata de uma sociedade enferma ou podemos dizer de uma sociedade que não respeita a autopoiese dos seus indivíduos que, por sua vez, deixam de se ver como iguais (MATURANA; VARELA, 2005).

A ciência pensou ser possível resolver desafios complexos por meio do pensamento linear, das facilidades da padronização, da segurança e controle (MORIN, 2007). A existência humana é complexa e a busca pela liberdade individual tem tido como resultado mais insegurança: seja de forma individual, internalizada pelos indivíduos (medo, insegurança, insatisfação, patologias psíquicas ou físicas); seja socialmente através de diferenças sociais, discriminação, intolerância, competitividade e indiferença (BAUMAN, 1998, 2004).

Porém, esse contexto não inviabiliza a tese de Maturana e Varela (1997, 2005), pelo contrário, pois o homem continua procurando meios de desenvolver sua autopoiese, sua autonomia e liberdade; por vezes encontrando, outras não. Tanto que em meio ao ambiente hostil continua emergindo a crítica, intuitos de transformação, de ajuda, vínculos dos mais variados, discussões sobre a possibilidade de uma Economia Social e Solidária.

De acordo com Maturana e Varela (2005) é preciso conhecer e nos reconhecer como seres vivos, autônomos, (auto)-criadores, mas construídos e reconstruídos com os outros, inseridos no mundo, assumindo as responsabilidades de nossas ações. Isto implica um ideal de liberdade diferenciado, não a liberdade individualizada, que prescinde dos outros, mas uma liberdade com os outros, através deles e da natureza e que, por isto mesmo, não pode ocorrer de outra maneira, senão numa base ética e cooperativa. Ainda que se assuma o individualismo, competitividade, egoísmo, vontade de poder como expressões humanas, também o são cooperatividade, altruísmo, sociabilidade.

\section{Considerações Finais}

A ciência pensou ser possível resolver desafios complexos por meio do pensamento linear, das facilidades da padronização, da segurança e controle (MORIN, 2007). No entanto, em diversas áreas das ciências surgiram características sistêmicas que não se enquadravam no método analítico dominante e não havia uma teoria ou um método que tornasse possível uma modelização sistêmica. 
O trabalho de Bertalanffy (1973) foi considerado pioneiro nesse sentido, ainda que sua proposta de uma General System Theory tenha sido considerada pretensiosa por parte da comunidade científica, o tratamento organísmico que deu aos sistemas abertos trouxe avanços consideráveis. Desde então, ocorreu um esforço científico que contribuísse com o desenvolvimento de uma metodologia que tornasse possível a pesquisa do Sistema Geral, representado muito mais por uma descrição do que por uma definição, intencionalmente generalizante, mas suficiente para reconhecer um objeto sistêmico. Esse método recupera e reconhece a engenhosidade do pesquisador: dotado de um projeto do objeto que modeliza ou uma concepção do fenômeno que observa, exigindo conhecimento suficiente para interpretar e antecipar seu comportamento. Tal modelo traz reflexões importantes em relação ao fazer científico dominante e, de modo especial, à pesquisa qualitativa (ao tratar da concepção fenômenos sociais ou coletivos, por exemplo), pois (re)introduz a complexidade e a autonomia, tanto do fenômeno, quanto do próprio pesquisador.

O aprofundamento das teorias sistêmicas de Maturana e Varela (1997, 2005) trazem contribuições não só para o fazer científico, mas questões filosóficas do fazer e aprender humanos no mundo, como parte dele, dependente da natureza e dos outros, com eles aprendendo e evoluindo. Essas teorias revertem o tratado científico como tem vigorado até então, realocando o homem e suas responsabilidades como parte da natureza. Uma transformação urgente para a ciência, uma transformação urgente de humanidade.

\section{Referências}

BAUER, R. Gestão da mudança: caos e complexidade nas organizações. 1. ed. São Paulo: Atlas, 1999.

BAUMAN, Z. O Mal-Estar da Pós Modernidade. 1. ed. Rio de Janeiro: Jorge Zahar Ed, 1998. BAUMAN, Z. Amor Líquido. 1. ed. Rio de Janeiro: Jorge Zahar Ed, 2004.

BERTALANFFY, L. V. Teoria Geral dos Sistemas. 1. ed. Petrópolis: Vozes, 1973.

FROMM, E. Psicanálise da Sociedade Contemporânea. 10. ed. Rio de Janeiro: Zahar Editores, 1983.

KUHN, T. S. A Estrutura das Revoluções Científicas. 9. ed. São Paulo: Perspectiva, 2006.

LE MOIGNE, J. L. O Construtivismo dos Fundamentos. Vl. I. Lisboa: Instituto Piaget, 1994.

LE MOIGNE, J. L. A Teoria do Sistema Geral. 1. ed. Lisboa: Instituto Piaget, 1996. 
LUHMANN, N. Introdução à teoria dos sistemas. 2. ed. Petrópolis: Vozes, 2010.

MARIOTTI, H. Autopoiese, Cultura e Sociedade. 1999. Disponível em:

<http://www.dbm.ufpb.br/ marques/Artigos/Autopoiese.pdf> Acessado em: 15 mar. 2017.

MARIOTTI, H. Prefácio. In: MATURANA, H.; VARELA, F. A Árvore do Conhecimento: as bases biológicas da compreensão humana. 5. ed. São Paulo: Palas Athenas, 2005. p.7-17.

MATURANA, H.; VARELA, F. De Máquinas e Seres Vivos: Autopoiese, a organização do vivo. 1. ed. Porto Alegre: Artes Médicas, 1997.

MATURANA, H.; VARELA, F. A Árvore do Conhecimento: as bases biológicas da compreensão humana. 5. ed. São Paulo: Palas Athenas, 2005.

MORIN. E. Introdução ao Pensamento Complexo. 3. ed. Porto Alegre: Sulina, 2007.

WEBERING, S. I. Paradigma Sistêmico: origens e desdobramentos. In: CONGRESSO IBERO-AMERICANO EM INVESTIGAÇÃO QUALITATIVA, 5, 2016, Porto. Atas do... São Roque: Ludomedia, 2016. p. 610-618.

Recebido em: 26 de março de 2017.

Aceito em: 22 de maio de 2017. 